\title{
PROAPOPTOTIC EFFECT OF ATORVASTATIN ON STIMULATED RABBIT SMOOTH MUSCLE CELLS
}

\author{
ROBERTA BAETTA, ELENA DONETTI, CARMEN COMPARATO, \\ MONICA CALORE, ALESSANDRA ROSSI, CHIARA TERUZZI, \\ RODOLFO PAOLETTI,REMO FUMAGALLI and MAURIZIO R. SOMA*
}

Institute of Pharmacological Sciences, University of Milan, Milan, Italy

Accepted 8 July 1997

\begin{abstract}
The in vitro and in vivo activity of atorvastatin and other 3-hydroxy-3-methylglutaryl coenzyme A (HMGCoA) reductase inhibitors (fluvastatin, pravastatin and simvastatin) has been investigated. Atorvastatin, fluvastatin, pravastatin and simvastatin caused a significant and dose-dependent $(0.1-50 \mu \mathrm{M})$ reduction in cell multiplication of vascular smooth muscle cells (SMC) in cultures associated with the retardation of cycling cells in the G1 and G2/M compartments at $24 \mathrm{~h}$, a phenomenon leading to apoptosis (programmed cell death) in several experimental in vitro models. The effects on the cell cycle resulted in a strong inhibition of cell proliferation at $48 \mathrm{~h}$, followed by apoptosis when incubation was prolonged to $72 \mathrm{~h}$ as assessed by nuclei morphology and cytofluorimetric analysis of DNA. The apoptotic effect observed for the statins is completely prevented by the addition of exogenous mevalonate at a $100 \mu \mathrm{M}$ concentration. In vivo SMC proliferation was stimulated by applying a silastic collar to the outside surface of carotid arteries in normocholesterolemic rabbits in the presence of an anatomically intact endothelium. The positioning of the collar promoted apoptosis in control vessels as assessed by Terminal Deoxynucleotidyl Transferase-dUTP-Biotin Nick-End Labeling (TUNEL) assay. The pre-treatment with $5 \mathrm{mg}$ $\mathrm{kg}^{-1}$ per day of atorvastatin before collar insertion strongly increased the number of TUNEL-positive cells, suggesting a pro-apoptotic effect of HMGCoA reductase inhibitors also in vivo, even though cell DNA rearrangement still needs to be excluded. No apoptotic signal was detectable in sham operated arteries with no collar in either control or atorvastatin-treated rabbits. These data indicate that HMGCoA reductase inhibitors effect on the arterial wall may involve the modulation of both cell proliferation and programmed cell deaths supporting a possible role of statins in the prevention of early lesion and restenosis.

(c) 1997 The Italian Pharmacological Society
\end{abstract}

KEY WORDS: apoptosis, smooth muscle cells, atherosclerosis, HMGCoA reductase inhibitors, atorvastatin.

\section{INTRODUCTION}

Dynamic and continued 'stress events' represented by either chemical or mechanical risk factors or alterations of the physiological balance in the arterial wall promote functional endothelium injury and thus migration and multiplication of smooth muscle cells (SMC) and apoptosis [1]. SMC proliferation and intimal hyperplasia is a prominent feature in human and experimental atherosclerosis [2].

\footnotetext{
* Corresponding author. Institute of Pharmacological Sciences University of Milan, Via Balzaretti 9, 20133 Milan, Italy.

${ }^{1}$ Roberta Baetta and Elena Donetti contributed equally to this work and both should be considered as first authors.
}

Atherosclerosis occurs in the intima at sites of SMC proliferation and often in the presence of a continuous yet functionally and structurally altered endothelium. Smooth muscle cells contribute to the lesion by cell accumulation and extracellular matrix production and secretion [1]. The control of the proliferative process is presently considered a favourable component of potential antiatherosclerotic drugs [3]. The occurrence of apoptosis in normal and especially in rapidly proliferating cell populations suggests a potential role of this process in the maintenance of stable numbers of normal cells in tissues with various degrees of proliferative activity, including the arterial wall [4, 5]. Apoptosis is an important regulator of cell number in the vessel 
wall, balancing cell proliferation and thus helping to maintain vessel wall architecture [4]. Cell kinetic studies indicate a tight link between vascular SMC rate of formation and death in normal arteries [6, 7], a link that may be lost upon the development of atherosclerosis $[4-6,8,9]$.

We have recently observed that several 3-hydroxy3-methylglutaryl coenzyme A (HMGCoA) reductase inhibitors are able to affect smooth muscle cell proliferation in the carotid artery intima of normocholesterolemic rabbits who had a silastic collar placed on them [10], by mechanisms independent from serum lipoprotein lowering, possibly through the local inhibition of mevalonate biosynthesis [11]. We also reported that statin-treated C6 glioma cells show the inhibition of cell cycling in G1 and arrest/retardation in $\mathrm{G} 2 / \mathrm{M}$ both in vitro and in vivo, a phenomenon often associated with apoptosis [12]. Furthermore, an apoptotic effect of lovastatin, an HMGCoA reductase inhibitor, has already been described in HL-60 [13], leukaemic [14] and human glioma cells [15].

In the present study, SMC apoptosis in tissue culture and in vivo has been investigated. In vivo SMC proliferation was stimulated by the silastic collar method. The positioning of the collar promotes an early infiltration of the vessel wall by polymorphonuclear cells and monocytes, followed by smooth muscle cell replication in the media and gradual subendothelial smooth muscle cell accumulation, with deposition of extracellular matrix within the neointima [10]. The effect of statins (atorvastatin, fluvastatin, pravastatin and simvastatin) on in vitro and in vivo SMC apoptosis has been evaluated.

\section{MATERIALS AND METHODS}

\section{Materials}

Tissue culture plastics were from Corning (Corning, NY, USA). Atorvastatin, fluvastatin, pravastatin and simvastatin were from Parke-Davies, Novartis (Basel, Switzerland), Bristol Mayers Squibb and Merck, Sharp and Dohme (Rahway, NJ, USA). Mevalonic acid lactone and all materials for flow cytometry were from Sigma Chemical Co. (St. Louis, MO, USA). The TUNEL kit was supplied from Boeringher-Mannheim.

\section{Cell culture}

Smooth muscle cells were cultured according to Ross [16], from the intima-media layers of the common carotid of male New Zealand rabbits weighing 2-2.3 kg (Charles River, Calco, Italy) as previuosly described [17]. Cells were maintained in monolayer culture at $37^{\circ} \mathrm{C}$ in a humidified atmosphere containing $5 \% \mathrm{CO}_{2}$ in Dulbecco's minimum essential medium (Gibco Laboratories, Grand Island, NY, USA) supplemented with $10 \%$ foetal calf serum, penicillin-streptomycin, sodium piruvate (Gibco). Cells were maintained. At confluence, cultures were repleted by enzymatic dissociation with trypsin/EDTA (Gibco). All experiments were performed within the 10th subculture.

Atorvastatin and fluvastatin were diluted in methanol (final concentration 0.1\%) and added in required amounts to the culture media. Pravastatin was dissolved in PBS. Simvastatin was added to the cultures as the sodium salt, obtained from the lactone according to the procedure of Kita et al. [18]. In each experiment, proper control cell dishes incubated with methanol $(0.1 \%)$ were included.

Cell viability was determined by the Trypan blue exclusion methods as previously described [19].

\section{Cell cycle analysis}

Approximately $10^{6}$ cells per experimental condition were harvested by trypsinization, washed with $0.1 \mathrm{M}$ phosphate-buffered saline (PBS) and subsequently fixed in $70 \%$ cold ethanol. Propidium iodide staining and DNA analysis by flow cytometry were carried out as previously described [12].

\section{Myocyte proliferation}

Myocytes were seeded in triplicate in $35-\mathrm{mm}$ tissue culture dishes at a density of about 150,000 cells per dish and after $24 \mathrm{~h}$ received drug treatment as described in the Results section. The cell number was determined using a Coulter counter (Coulter Instruments, Milan, Italy) following tryspinization.

\section{Visualization of apoptotic nuclei}

Smooth muscle cells were grown on coverslips and treated as described in the text. Cells were fixed with $70 \%$ cold ethanol and stained with the DNA intercalating dye Hoechst 33528, $0.5 \mu \mathrm{g} \mathrm{ml}^{-1}$ in PBS containing $100 \mu \mathrm{g} \mathrm{ml}^{-1}$ DNase-free RNase A (Sigma Chemical Co.) and $0.1 \%$ NP40. The coverslips were rinsed, air dried and mounted with Permafluor mounting medium (Immunon, Pittsburgh, PA, USA). Fluorescence was visualized using a Zeiss Axioskop microscope.

\section{Neointimal hyperplasia}

New Zealand rabbits (approx. $2 \mathrm{~kg}$ in weight) were used. The animals were randomly separated into two groups (three animals per group): (1) control animals; (2) atorvastatin, $5 \mathrm{mg} \mathrm{kg}^{-1}$ per day continuous i.p. infusion for 7 days.

At day 5 a silastic collar of $1.5 \mathrm{~cm}$ in length was inserted on the left carotid artery, essentially as described [10]. The contralateral artery was identically manipulated but no collar was left on (sham). Animals were killed 3 days after collar positioning. 
Terminal Deoxynucleotidyl TransferasedUTP-Biotin Nick-End Labeling (TUNEL) assay

Paraffin sections were dewaxed, rehydrated, treated with proteinase $\mathrm{K}\left(20 \mu \mathrm{g} \mathrm{ml}^{-1}\right)$ and blocked for endogenous peroxidase activity with $3 \% \mathrm{H}_{2} \mathrm{O}_{2}$. After end-labelling for $1 \mathrm{~h}$ at $37^{\circ} \mathrm{C}$ according to the kit instructions, sections were washed in PBS and incubated with anti-fluorescein antibody conjugated with horseradish peroxidase complex, rinsed in PBS and stained with DAB substrate. Apoptotic nuclei were identified by the presence of fluorescent staining.

\section{RESULTS}

\section{Statin-induced apoptosis: cell cycle distribu-} tion analysis

The DNA histograms obtained from smooth muscle cells treated for $24 \mathrm{~h}$ with atorvastatin $(1-10 \mu \mathrm{M})$ showed a dose-dependent drug effect on the cell cycle distribution (Fig. 1, upper panel). The entry of cells into the $\mathrm{S}$ phase progressively decreased. At a concentration above $1 \mu \mathrm{M}$ the $\mathrm{G} 0 / \mathrm{G} 1$ block was accompanied by an increase of the proportion of cells in $\mathrm{G} 2 / \mathrm{M}$, as indicated by the decline of the $\mathrm{S}: \mathrm{G} 2 / \mathrm{M}$ ratio. When incubation with atorvastatin was prolonged up to $72 \mathrm{~h}$ the $\mathrm{G} 2 / \mathrm{M}$ peak declined coincident with the appearance of a dose-dependent sub-diploid peak (sub G1), typical of apoptotic cells, starting from a concentration of $5 \mu \mathrm{M}$ (Fig. 1, lower panel). The addition of mevalonate to cultured cells completely abolished the effects of atorvastatin on cell cycle distribution and DNA content (Fig. 1). Simvastatin, pravastatin and fluvastatin showed a similar pattern on the cell cycle.

\section{Antiproliferative effect of statins on SMC}

Smooth muscle cells were treated in culture with increasing concentrations of either atorvastatin, fluvastatin, pravastatin or simvastatin and the cell number was determined after $48 \mathrm{~h}$. Exposure to either statin resulted in a dose-dependent inhibition of cell growth rates as shown in Fig. 2. A similar pattern, somehow more effective for simvastatin, was observed for all statins. The addition of mevalonate $(100 \mu \mathrm{M})$ to cells exposed to the statins completely abolished the antiproliferative effect observed (Fig. 2).
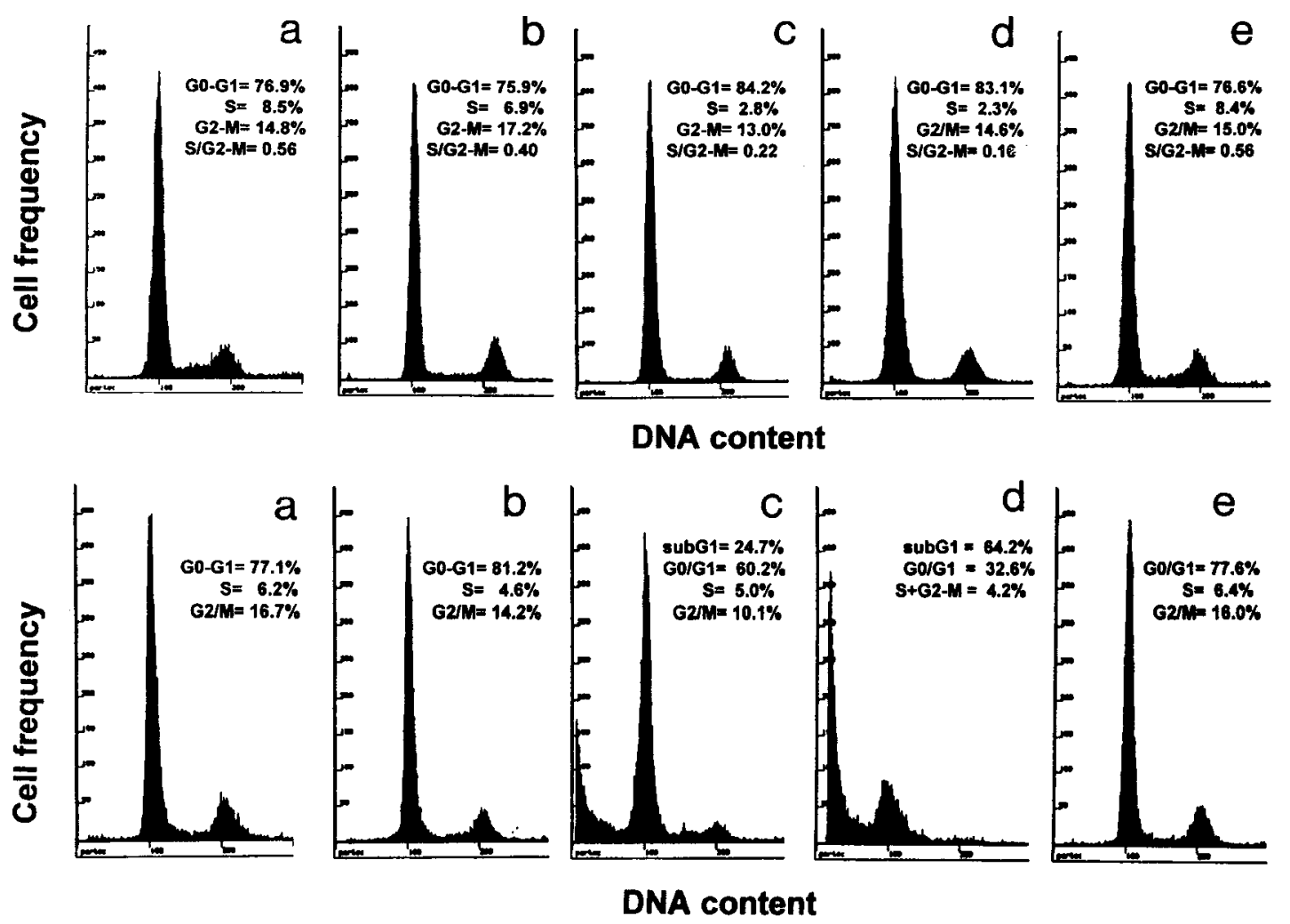

Fig. 1. In vitro effect of atorvastatin on DNA frequency distribution histograms of rabbit SMC. Exponentially growing cells were incubated for $24 \mathrm{~h}$ (upper panel) or $72 \mathrm{~h}$ (lower panel) in the presence of various concentrations of atorvastatin. The DNA content was analyzed by flow cytometry after propidium iodide staining. a, controls; b, $1 \mu \mathrm{M}$ atorvastatin; c, $5 \mu \mathrm{M}$ atorvastatin; $\mathrm{d}, 10 \mu \mathrm{M}$ atorvastatin; e, $10 \mu \mathrm{M}$ atorvastatin plus $100 \mu \mathrm{M}$ MVA. Percentages of cells in different phases of the cell cycle are given in each panel. Similar results were obtained in six independent experiments. The sub-dipolid peak in DNA frequency distribution histograms from $72 \mathrm{~h}$ treated cells indicates the presence of apoptotic nuclei. 
Morphological analysis and effect on cell viability in statin-treated cells

The induction of apoptosis by atorvastatin was also detected in smooth muscle cells by micronucleation after staining with the DNA intercalating dye Hoechst 33528 (Fig. 3). Cell viability, determined by the Trypan blue exclusion assay, was always greater than $80 \%$ under all experimental conditions (data not shown).

\section{Statin-induced apoptosis: in vivo effect}

The neointimal hyperplastic lesion composed of vascular smooth muscle cells was generated by applying a silastic collar to the outside of normocholesterolemic rabbit carotid arteries. Rabbits were killed 24 and $72 \mathrm{~h}$ after collar surgery. The positioning of the collar promoted an early infiltration of the vessel wall by polymorphonuclear cells and monocytes ( 24 $\mathrm{h}$ after collar placement), followed by smooth muscle cell replication in the media and a gradual subendothelial smooth muscle cell accumulation, with deposition of extracellular matrix within the neointima. Apoptotic cells were detectable starting $24 \mathrm{~h}$ after collar positioning. Figure 4 (A) is an overview at low magnification illustrating the general distribution of TUNEL labelling of nuclei for internucleosomally degraded DNA indicating apoptosis at day 3 in control collared arteries. Labeling was prominent in the outer media. Carotid arteries obtained from rabbits treated with either atorvastatin or fluvastatin $\left(5 \mathrm{mg} \mathrm{kg}^{-1}\right.$ per day) starting 5 days prior to collar insertion revealed a stronger TUNEL labelling [Fig. 4 (B)], compared to controls, which was especially apparent in the outer media but common also elsewhere. No apoptosis signal was detectable in arteries with no collar from either control or statin-treated rabbits.

\section{DISCUSSION}

We have recently reported an in vitro and in vivo inhibition of vascular SMC proliferation by HMGCoA reductase inhibitors independent of their hypocholesterolemic properties [10]. The present study indicates programmed cell death as an additional possible mechanism for the modulation of the cellularity of the arterial wall in proliferative atherosclerotic or restenotic lesions where the SMC component is predominant. These results and previous in vitro and in vivo observations [10,11] demonstrate a direct effect by statins on the arterial wall which merits clinical investigation.

HMGCoA reductase inhibitors have received increasing attention as pharmacological tools for con-

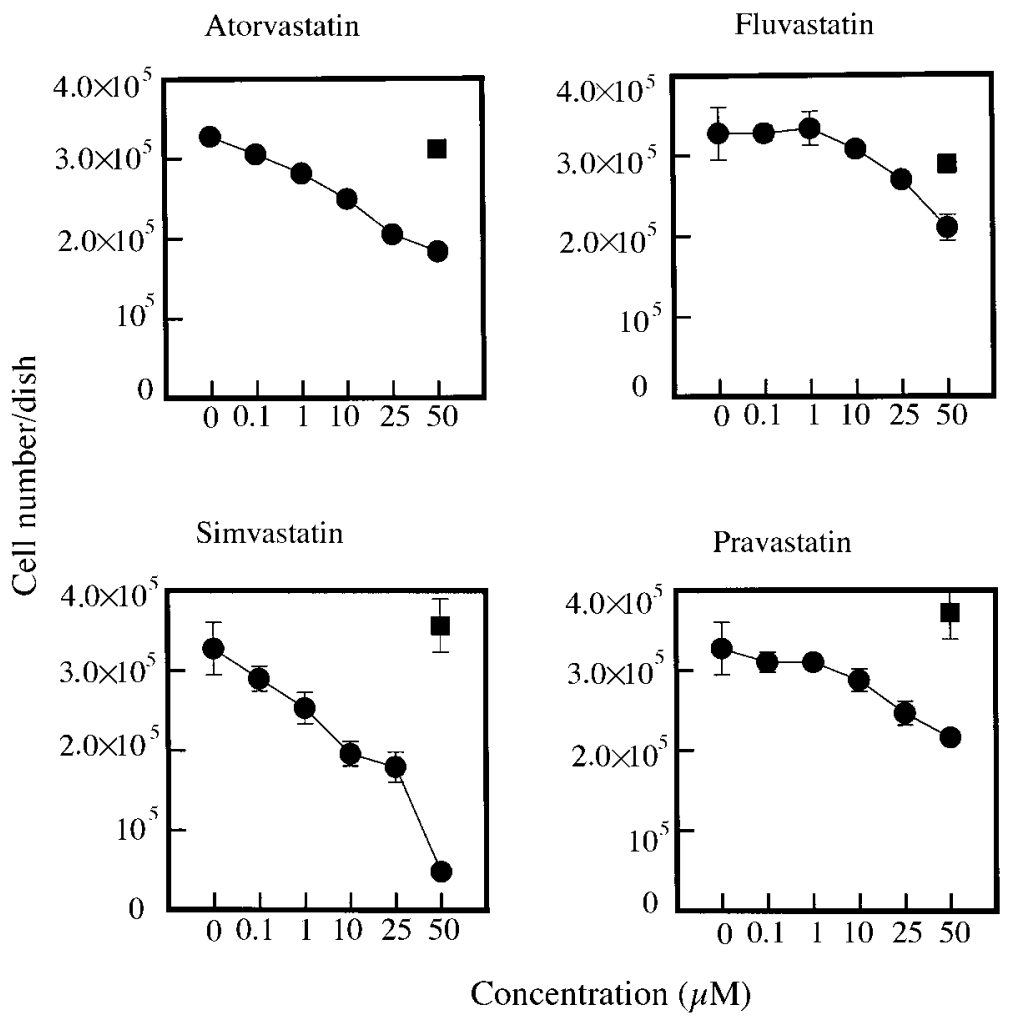

Fig. 2. Dose-dependent effect of different statins on SMC proliferation at $48 \mathrm{~h}$. Exponentially growing cells were incubated for $48 \mathrm{~h}$ with increasing concentrations of statins in the presence ( $\boldsymbol{\square})$ or absence (O) of $100 \mu \mathrm{M}$ mevalonate. 

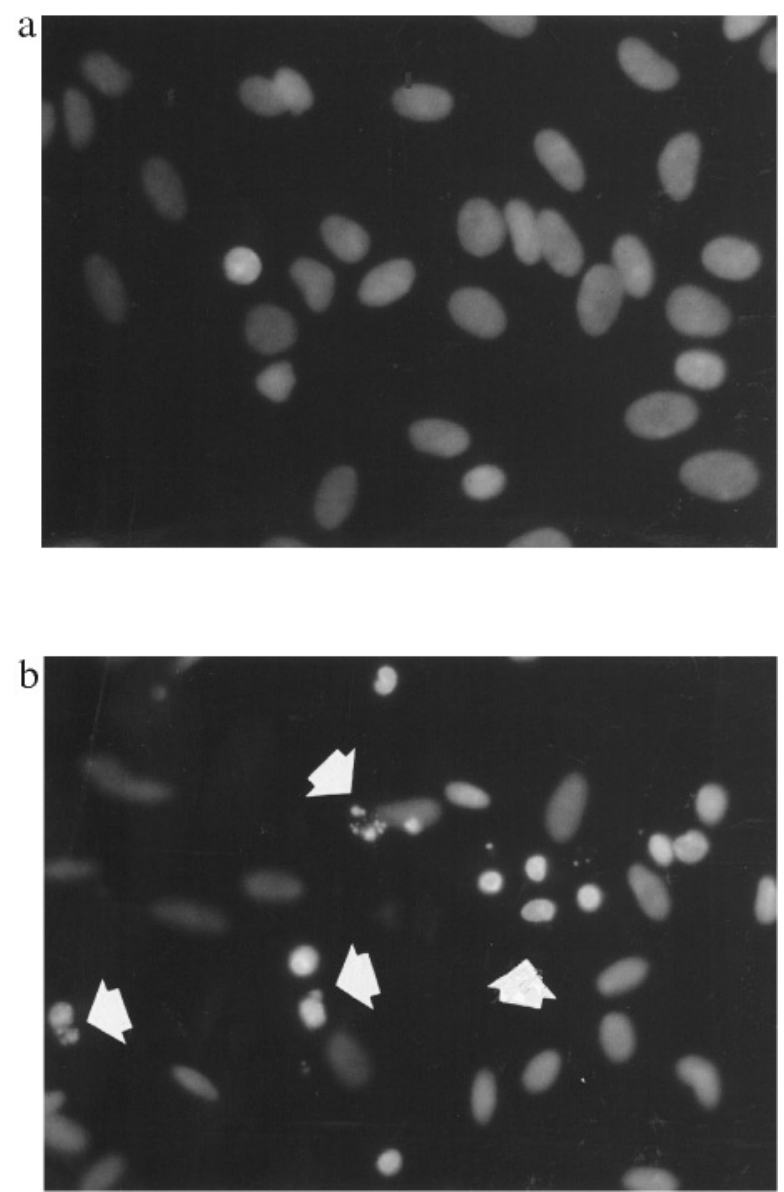

Fig. 3. Induction of apoptosis by atorvastatin: morphological analysis of Hoechst 33528-stained nuclei. SMC were treated for $72 \mathrm{~h}$ with $5 \mu \mathrm{M}$ atorvastatin. Cells were fixed with $70 \%$ ice-cold ethanol and stained with Hoechst 33528. Fluorescence was visualized using a Zeiss Axioskop microscope (Objective PlanNeofluar 40X). a, untreated SMC; b, treated SMC. Apoptotic cells are indicated by arrows.

trolling abnormal cell growth, such as myocyte proliferation in atherogenesis $[3,10]$ or tumor development $[12,20]$.

Several in vitro and pre-clinical evidence support the hypothesis of a direct effect of statins on the arterial wall [3]. Recent in vitro studies demonstrate that statins dose-dependently decrease SMC migration and proliferation [17]. Pre-clinical data show that HMGCoA reductase inhibitors, albeit with different potencies, decrease neointimal proliferation in both hypercholesterolemic [21-24] and normocholesterolemic rabbits without affecting, in this case, plasma cholesterol levels [10]. The latter study suggests that these drugs can directly affect early alteration of wall responses irrespective of plasma lipid changes. Indeed in vivo data demonstrate that the mechanism underlying the antiproliferative effect of statins is related to the local inhibition of MVA synthesis within cells of the vascular wall, since local delivery of MVA fully prevented the inhibitory ef-
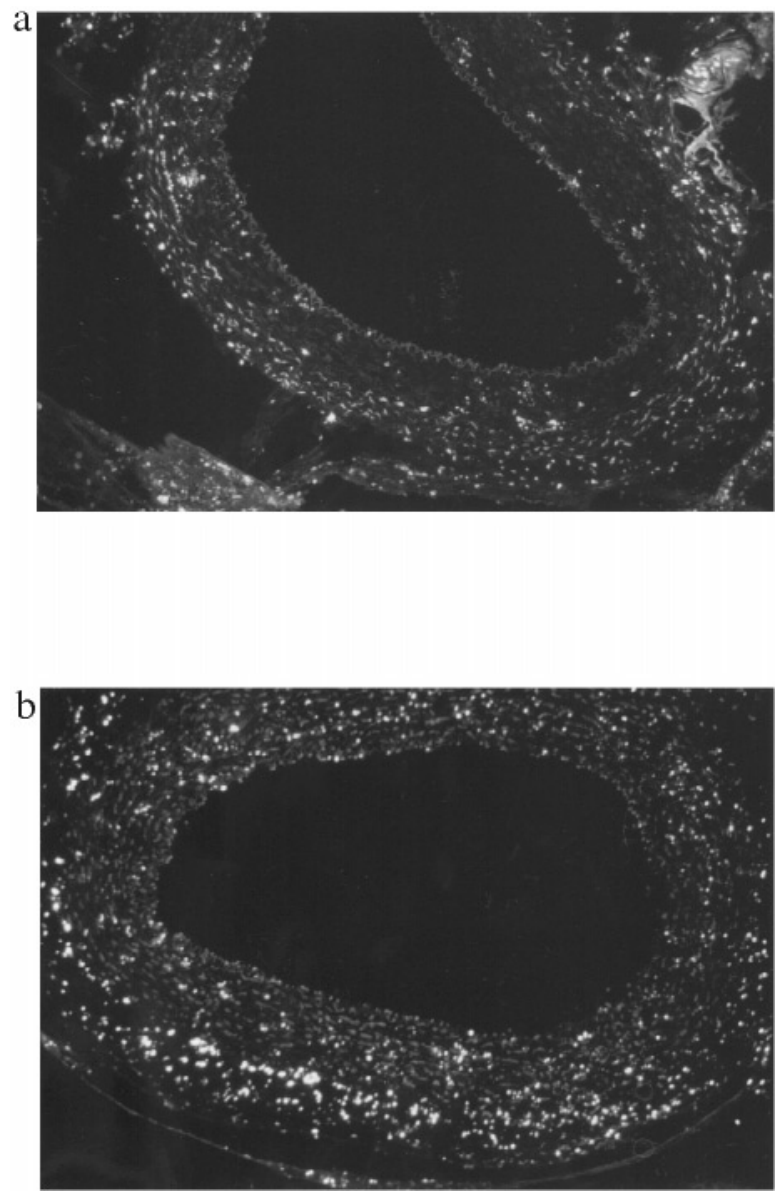

Fig. 4. Detection of apoptosis in collared arteries from normocholesterolemic rabbits 3 days after perivascular manipulation. Staining with TUNEL demonstrates the presence of fragmented nuclei. Fluorescence was visualized using a Zeiss Axioskop microscope (Objective PlanNeofluar 20X). a, carotid section from the control rabbit; $\mathrm{b}$, carotid section from a rabbit treated with $5 \mathrm{mg} \mathrm{kg}^{-1}$ day of atorvastatin starting 7 days before collar positioning.

fect of systemic fluvastatin [11]. It is well known that mevalonate is the precursor of a complex branched pathway the major product of which is cholesterol. However, mevalonate is also the precursor of a variety of essential non-sterol isoprenoids including: the polyisoprenoids side chains of heme $\mathrm{A}$ and ubiquinone, involved in oxidative respiration; dolichol, required for glycoprotein synthesis; and isopentenyl-adenine, present in some transfer RNAs. Furthermore, mevalonate is the precursor of two isoprenoids intermediates, farnesyl-pyrophosphate (C15) and geranylgeranyl-pyrophosphate (C20), substrates for a post-translational modification in which the lipid moiety is covalently transferred to cellular proteins fundamental for cell function secretion, migration and proliferation and proliferation [20].

In the present study statins were used in rabbit smooth muscle cell cultures; however, similar results were obtained with human SMC (unpublished data). 
Statin concentrations utilized in both rabbit and human SMC were comparable to the peak plasma concentrations $(0.1-1 \mu \mathrm{M})$ transiently achieved in the plasma of hypercholesterolemic patients treated with $160 \mathrm{mg}$ per day of simvastatin [25]. Previous in vitro results demonstrated that the inhibition of cell growth correlates with intracellular HMGCoA reductase activity and takes place as long as mevalonate biosynthesis remains inhibited by at least $60-70 \%$ [27]. These observations suggest the use of HMGCoA reductase inhibitors either with very high in vivo efficacy or at very high doses and favour an uninterrupted administration to maintain biological activity by sustained mevalonate pathway inhibition. This could translate into a more significant prevention of cardiovascular disease [3].

The results of the present study indicate that statins play an important role on cell cycle progression and apoptosis in SMC. In fact, the exposure of SMC to statins induces at $24 \mathrm{~h}$ a dose-dependent decrease in $\mathrm{S}$ phase and an accumulation of the cells in $\mathrm{G} 2 / \mathrm{M}$, particularly at the highest concentrations. This results in an inhibitory effect on cell proliferation at $48 \mathrm{~h}$, followed by apoptosis when incubation is prolonged to $72 \mathrm{~h}$ [Figs. 1 and 2]. Atorvastatin and fluvastatin systemic pre-treatment increased the number of TUNEL positive cells suggesting a proapoptotic effect of HMGCoA reductase also in vivo, at least under our experimental conditions, even though cell DNA rearrangement cannot be completely excluded.

In conclusion these data, together with previous results, suggest that the HMGCoA reductase inhibitors effect on the arterial wall may involve modulation of both cell proliferation and apoptotic cell death. Thus, statins merit further investigation as preventive approaches to early lesion development and restenosis.

\section{ACKNOWLEDGEMENTS}

This research was partially supported by BIOMED 2 PL 950329, CNR 'Cell cycle and apoptosis' and MURST (Italy).

\section{REFERENCES}

1. Ross R. The pathogenesis of atherosclerosis: a perspective for the 1990s. Nature 1993; 362: 801-9.

2. Raines EW, Ross R. Smooth muscle cells and the pathogenesis of the lesions of atherosclerosis. $\mathrm{Br}$ Heart J 1993; 69: S30-7.

3. Soma MR, Paoletti R. Resume of the future of cardiovascular disease - prevention and the role of lipid regulation. Cardiovasc Risk Factors 1996; 6: 262-8.

4. Isner JM, Kearney M, Bortman S, Passeri J. Apoptosis in human atherosclerosis and restenosis. Circulation 1995; 91: 2703-11.
5. Han DKM, Haudenschild CC, Hong MK, Tinkle BT, Leon MB, Liau G. Evidence for apoptosis in human atherogenesis and in a rat vascular injury model. $\mathrm{Am}$ J Pathol 1995; 147: 267-77.

6. Bennett MR, Evan GI, Schwartz SM. Apoptosis of human vascular smooth muscle cells derived from normal vessels and coronary atherosclerotic plaques. J Clin Invest 1995; 95: 2266-74.

7. Cho A, Courtman D, Langille L. Apoptosis (programmed cell death) in arteries of the neonatal lamb. Circ Res 1995; 76: 168-75.

8. Kockx MM, Cambier BA, Bortier HE, De Meyer GR, Declercq SC, Van Cauwelaert PA, Bultinck J. Foam cell replication and smooth muscle cell apoptosis in human saphenous vein grafts. Histopathology 1994; 25: 365-71.

9. Geng Y-J, Libby P. Evidence for apoptosis in advanced human atheroma. Colocalization with interleukin-1beta-converting enzyme. Am J Pathol 1995; 147: $251-66$.

10. Soma MR, Donetti E, Parolini C, Mazzini G, Ferrari C, Fumagalli R, Paoletti R. HMG CoA reductase inhibitors: in vivo effects on carotid intimal thickening in normocholesterolemic rabbits. Arterioscl Thromb 1993; 13: 571-8.

11. Soma MR, Parolini C, Donetti E, Fumagalli R, Paoletti R. Inhibition of isoprenoid biosynthesis and arterial smooth muscle cell proliferation. J Cardiovasc Pharmacol 1995; 25: S20-4.

12. Soma MR, Baetta R, de Renzis MR, Mazzini G, Davegna C, Magrassi L, Butti G, Pezzotta S, Paoletti $\mathrm{R}$, Fumagalli R. In vivo enhanced antitumor activity of carmustine [ $N, N^{\prime}$-Bis(2-chloroethyl)- $N$-nitrosourea] by simvastatin. Cancer Res 1995; 55: 597-602.

13. Perez-Sala D, Collado-Escobar D, Mollinedo F. Intracellular alkalinization suppresses Lovastatin-induced Apoptosis in HL-60 cells trough the inactivaction of a $\mathrm{pH}$-dependent endonuclease. J Biol Chem 1995; 270: 6235-42.

14. Bansal N, Houle AG, Melnykovgch G. Comparison of dexamethasone and lovastatin (mevinolin) as growth inhibitors in cultures of T-cell derived human acute leukemia lines (CEM). Leukemia Res 1989; 13: 875-882.

15. Jones KJ, Couldwell WT, Hinton DR, Su Y, He S, Anker L, Law RE. Lovastatin induces growth inhibition and apoptosis in human malignant glioma cells. Biochem Biophys Res Commun 1994; 205: 1681-7.

16. Ross R. The smooth mucle cells. II. Growth of smooth muscle cells in culture and formation of elòastic fibers. J Cell Biol 1971; 50: 172-86.

17. Corsini A, Mazzotti M, Raiteri M, Soma MR, Gabbiani G, Fumagalli R, Paoletti R. Relationship between mevalonate pathway and arterial myocyte proliferation: in vitro studies with inhibitors of HMG-CoA reductase. Atherosclerosis 1993; 101: 117-25.

18. Kita T, Brown MS, Goldstein JL. Feedback regulation of HMGCoA reductase in livers of mice treated with mevinolin, a competitive inhibitor of the reductase. J Clin Invest 1980; 66: 1094-100.

19. Ian Freshney R: Trypan Blue Dye exclusion method. In: Ian Freshney R, ed. Culture of Animal Cells. A Manual of Basic Technique. New York: ARL, 1986: pp. 208-9.

20. Goldstein JL, Brown MS. Regulation of the mevalonate pathway. Nature 1990; 343: 425-30.

21. Osborne JA, Lento PH, Siegfried MR, Stahl GL, Fusman B, Lefer AM. Cardiovascular effects of acute 
hypercholesterolemia in rabbits. Reversal with lovastatin treatment. J Clin Invest 1989; 83: 465-73.

22. Gellman J, Ezekowitz MD, Sarembock IJ, Azrin MA, Nochomowitz LE, Lerner E, Haudenschild CC. Effect of lovastatin on intimal hyperplasia after balloon angioplasty. A study in an atherosclerotic hypercholesterolemic rabbit. J Am Coll Cardiol 1991; 17: 251-9.

23. Zhu BQ, Sievers RE, Sun YP, Isenberg WM, Parmley WW. Effect of lovastatin on suppression and regression of atherosclerosis in lipid-fed rabbits. $J$ Cardiovasc Pharmacol 1992; 19: 246-55.

24. Azarin MA. Effect of lovastatin on intimal hyperplasia after balloon angioplasty: a study in an atherosclerotic hypercholesterolemic rabbit. J Am Coll Cardiol 1991; 17: 251-9.

25. Davidson MH, Stein EA, Dujovne C, Hunninghake
DB, Weiss SR, Knopp RH, Illingworth DR, Mitchell B, Melino MR, Zupkis RW, Dobrinska MR, Amin $\mathrm{RD}$, Tobert JA. The efficacy and six-week tolerability of simvastatin 80 and $160 \mathrm{mg} /$ day. Am J Cardiol 1997; 79: 38-42.

26. Thibault A, Samid D, Tompkins AC, Figg WD, Cooper MR, Hohl RJ, Trepel J, Liang B, Patronas N, Venzon DJ, Reed E, Myers CE. Phase I study of lovastatin, an inhibitors of the mevalonate pathway, in patients with cancer. Clin Cancer Res 1996; 2: 483-91.

27. Soma MR, Pagliarini P, Butti G, Paoletti R, Paoletti P, Fumagalli R. Simvastatin, an inhibitor of cholesterol biosynthesis, shows synergistic effect with $\mathrm{N}, \mathrm{N}^{\prime}$ Bis(2-chloroethyl)-N-nitrosourea and beta interferon on human glioma cells. Cancer Res 1992; 52: 4348-55. 